Aus dem Institut für Infektionskrankheiten in Berlin.

(Direktor: Geh. Ober-Med.-Rat Prof. Dr. Gaffky.)

\title{
Trypanosomen-Infektion und Komplement.
} bindung.

Von Dr. Claus Schilling, Leiter der Abteilung für Tropenkrankheiten, und Dr. v. Hoesslin.

Die Wirkung der krankheiterregenden Protozoen auf den Wirtsorganismus ist als durch Toxine veranlaßt zu betrachten. Dies geht unter anderem aus dem Umstande hervor, daß im Blute von mit Trypanosomen infizierten Tieren von Schilling, Martini, Kleine und Möllers u. a. agglomerierende und parasitizide Substanzen nachgewiesen worden sind, welche man als die Reaktionsprodukte des Körpers auf die Wirkung von spezifischen Substanzen, in diesem Falle von Toxinen auffaßt. Lueber hat diese Toxine in die vordere Augenkammer und unter die Conjunctiva von Kaninchen injiziert und charakteristische Hornhauttrübungen erzeugt. Neuere, noch unveröffentlichte Untersuchungen von Leber und Schilling zeigen, daß es sich dabei nur um eine Toxinwirkung handeln könne. Aehnliche Antikörper gegen Protozoen sind bei der Hundepiroplasmose nachgewiesen (Nocard, Theiler).

Aber es ist bis jetzt noch nicht gelungen, diese Toxine und die ihnen entsprechenden Antikörper anders als durch den Tierversuch nachzuweisen oder gar zu isolieren.

Die ersten Untersucher schon, z. B. Kautback, Durham und Blandford, haben ihr Augenmerk darauf gerichtet, mit negativem Resultat. 
Mayer (Hamburg) hat im Serum eines Nagana-infizierten Hundes Substanzen nachgewiesen. welche mit einem durch Trypsinverdauung hergestellten Trypanosomenextrakt Präzipitation ergaben. Von Schilling nachgeprüft, ergab dies Verfahren jedoch keine Fällung.

Landsteiner, Müller und Pötzl (1 u. 2) und Landsteiner und Müller (3) haben Sera von Kaninchen mit Hilfe der BordetGengouschen Komplementbindungsmethode untersucht, die sie mit Trypanosomen der Dourine (Tryp. equiperdum) und der menschlichen Trypanosomiasis (Schlafkrankheit, Tryp. gambiense) infiziert hatten. Zur Kontrolle untersuchten sie 23 normale Kaninchen; von diesen banden 13 das Komplement nicht, 8 nur schwach, 2 fast komplett. Zur Infektion mit Trypanosomen wurden dann nur solche Tiere verwendet, deren Serum kein oder nur spurenweise Komplement gebunden hatte. Schon 15-20 Tage nach der Einspritzung der Trypanosomen ergab die Prüfung der Sera auf ihre komplementbindende Kraft bei einem Tier komplette. bei vier Tieren fast kom. plette, bei einem starke Hemmung der Hämolyse. Von 14 Kanin. chen, bei denen die Zeit seit der Infektion nicht angegeben ist, trat bei 12 komplette, bei einem fast komplette und bei einem schwache Hemmung ein.

In einer Fußnote zu ihrer zweiten Mitteilung bemerken die Wiener Autoren noch, daß es scheine, als ob bei der Dourineinfektion die wirksamen Stoffe im Verlaufe der Krankheit abnehmen können.

Levi della Vida hat Meerschweinchen mit Trypanosomen der Nagana, des Mal de Caderas und Tryp. gambiense infiziert und ihr Serum geprüft. Als Antigen diente ihm getrocknetes und wieder gelöstes Pulver von Trypanosomen der betreffenden Art. Er fand niemals Bindung des Komplements.

Levaditi und Yamanouchi berichten über Komplementbindungsversuche mit Serum und Liquor cerebrospinalis bei drei mit Trypanosoma gambiense (Schlafkrankheit) Infizierten. Alle Kranken waren energisch mit Atoxyl behandelt worden, und seit langer Zeit waren keine Trypanosomen mehr bei ihnen nachzuweisen. Keiner von ihnen gab in seinem Serum eine Reaktion.

In einer zweiten Mitteilung berichten die gleichen Autoren über Versuche an Nagana- und Dourine-infizierten Kaninchen. Sie fanden, da $\beta$ normale Kaninchensera in Dosen bis 0,05 die Hämolyse mehr oder weniger aufheben. ') Durch Modifikationen der Versuchsanordnung gelang es, dieses Hindernis zu beseitigen. Von 11 infizierten Kaninchen ergaben 7 eine Komplementbindung, die "stärker war als mit normalem Serum". Aber die Autoren fügen hinzu, daß diese Reaktionen „le plus souvent peu marquées" waren. 4 Kaninchen, am 13.-30. Tage nach der Infektion geblutet, ergaben keinen positiven Ausschlag.

Fleis chmann gibt an, daß sieben normale Kaninchensera mit den verschiedensten Extrakten Komplementbindung zeigten.

Blumenthal fand die Reaktion bei normalen Kaninchen so stark, wie er sie bei syphilitischen Seris nie beobachtet hatte. Er führt sie auf die bei diesen Tieren konstatierte Coccidiosis zurück.

Hartoch und Yakim of haben ebenfalls mit Kaninchen gearbeitet und bei vier Tieren, die vor der Infektion kein komplementbindendes Serum besaßen, die Reaktion schon am elften Tag post infectionem auftreten sehen.

Bei der Infektion der Ratte mit Trypanosoma Lewisi entsteht, wie Rabinowitsch und Kempner zuerst nachwiesen, nach Ablauf der akuten Infektion eine Immunität gegen weitere Einverleibung von Trypanosomen derselben Art. In solchem Immunserum hat Manteufel versucht spezifische Ambozeptoren mit Hilfe der Komplementbindungsmethode nachzuweisen. Als Antigen verwendete er einen wäßrigen Extrakt von Blut, das die Erreger in großen Mengen enthielt. Er erhielt positive Ausschläge einerseits mit Lewisi-Immunserum gegen LewisiBlutextrakt, anderseits blieb diese Reaktion aber in einem zweiten Falle (Versuch VIII) gänzlich aus, und endlich ließen sich die gleichen positiven Resultate mit Lewisi-Immunserum und Dourine-Blutextrakt und sogar mit Serum einer gegen Zeckenfieber (Spirochaeta Duttoni) immunisierten Ratte erzielen. Demnach kann man diese Reaktionen nicht als spezifische betrachten.

Eine diagnostische Methode, die uns mit Sicherheit gestatten würde, die latente Trypanosomeninfektion beim Menschen

1) Es wäre sehr wünschenswert, wenn in allen Arbeiten über Komplementbindung mindestens ein Versuch mit allen Kontrollen in extenso angeführt würde, damit der Leser sich ein Bild von den Details, Titer des hämolytischen Serums etc., welche gerade hier von so großer Bedeutung sind, machen kann. und den Tieren mit Sicherheit zu ermitteln, würde die Bekämpfung dieser Seuchen auf eine ganz neue Basis stellen. Denn der negative Ausfall der mikroskopischen Untersuchung von Blut oder Drüsensaft beweist noch keineswegs, daß der Organismus tatsächlich frei von Parasiten sei. Und die Ueberimpfung von größeren Blutmengen auf empfängliche Versuchstiere ist zwar entscheidend, in der Praxis, wo man mit Tausenden von Infizierten zu rechnen hat, ist sie aber nicht durchführbar.

Untersuchungen mit der Bordet-Gengouschen Methode der Komplementbindung wurden deshalb in unserem Institute, wo wir sie im Jahre 1906 bereits in ähnlicher Weise begonnen, aber wegen der Ungleichmäßigkeit der Resultate und aus äuberen Gründen abgebrochen hatten, wieder aufgenommen. Hierbei haben Herr Geheimer Rat Prof. Dr. Wassermann und sein Assistent. Dr. G. Meier uns in der dankenswertesten Weise unterstützt.

Als Antigene kamen verschiedene alkoholische Leberextrakte von normalen und Trypanosomen-infizierten Kaninchen und Meerschweinchen, normalen und mit Babesia canis infizierten Hunden, von menschlicher cirrhotischer Luesleber sowie luetischer Fötalleber zur Verwendung. Die Anfertigung fand nach der Methode von Wassermann und Meier und von Porges und Meier statt. Ihre komplementbindende Eigenschaft wurde mit Hilfe von Serum von Syphilitischen ausprobiert. Die Extrakte zeigten sich zum Teil vollwertig. zum Teil als weniger brauchbar, wie in vielfachen Kontrollreihen ausgeprobt wurde, ohne daß ein besonderer Grund dafür angegeben werden kann.

Im allgemeinen kann man sagen, daß ein Extrakt, das bei luetischen Seris gut wirkt, auch bei Tierseris brauchbar ist, und umgekehrt. Kleine Differenzen in dieser Hinsicht kommen immerhin vor. Es soll hier nochmals betont werden, daß es für die Beurteilung der Resultate wichtig ist, daß die Untersuchungen vor und nach der Infektion mit dem gleichen Extrakt ausgeführt werden. Bei Benutzung verschiedener Extrakte, mögen sie auch gleich gut bei luetischen Kontrollseris wirken, können stets kleine Unterschiede vorkommen; aus diesen darf dann nicht sofort ein positiver oder negativer Ausschlag resp. Vermehrung oder Verminderung der Reaktionsprodukte herausgelesen werden.

Das hämolytische Serum wird in drei- bis vierfacher Konzentration genommen, doch ist es auch praktisch von nicht allzugroßer Bedeutung, ob hier mäßige Schwankungen nach oben stattfinden.

Es kamen Sera verschiedener mit Trypanosomen infizierter Tiere zur Prüfung: Rinder, Esel, Ziegen, Hunde, Kaninchen, Meerschweinchen und Ratten. Das Serum von Eseln, Ziegen und Hunden band das Komplement schon allein, ohne Antigenzusatz so stark, daß diese Tiere ausscheiden mußten. Ueber die Kaninclıensera gibt die Tabelle III Auskunft.

Für die Beurteilung der Versuchsergebnisse ist es von ganz wesentlicher Bedeutung, $\mathrm{zu}$ welcher Zeit man die Röhrchen kontrolliert; um dies zu erläutern, sei ein Protokoll in extenso angeführt:

\begin{tabular}{|c|c|c|c|c|c|c|}
\hline & Serum & $\begin{array}{c}\text { WäBriges } \\
\text { Extrakt aus } \\
\text { luetischer } \\
\text { Leber }\end{array}$ & $\begin{array}{c}\text { Hämolyt. } \\
\text { Serum } \\
\text { Titer }(1: 2000)\end{array}$ & $\begin{array}{l}\text { n. } 40^{\circ} \\
\text { bei } 37^{\circ}\end{array}$ & $\begin{array}{c}\text { nach } \\
\text { zwei } \\
\text { Stunden } \\
\text { bei } 37^{\circ}\end{array}$ & $\begin{array}{l}\text { danach } \\
24 \text { Stunden } \\
\text { im Eis- } \\
\text { schrank }\end{array}$ \\
\hline 1. Luetiker. & 0,2 & - & $4 \times$ Titer & gelöst & gelöst & gelöst \\
\hline $\begin{array}{ll} & \text { Serum } \\
\text { 2. } & \text { do. } \\
\text { 3. } & \text { do. } \\
\text { 4. } & \text { do. }\end{array}$ & $\begin{array}{l}0,2 \\
0,2 \\
0,2\end{array}$ & $\begin{array}{l}0,1 \\
0,05 \\
0,025\end{array}$ & $"$ & $\begin{array}{c}\text { ungelöst } \\
n \\
n\end{array}$ & $\begin{array}{c}\text { ungelöst } \\
n \\
n\end{array}$ & $\begin{array}{l}\text { ungelöst } \\
\text { ungelöst } \\
\text { ungelöst }\end{array}$ \\
\hline 5. - & - & 0,1 & " & gelöst & - & - \\
\hline 6. Serum von & 0,3 & 0,1 & n & ungelöst & fast ganz & gelöst \\
\hline $\begin{array}{l}\text { 7. do. } \\
\text { 8. } \\
\text { do. }\end{array}$ & $\begin{array}{l}0,2 \\
0,1\end{array}$ & $"$ & $"$ & etwas & gelöst & $"$ \\
\hline do. & 0,3 & - & n & $\begin{array}{l}\text { gelóst } \\
\text { gelöst }\end{array}$ & " & $n$ \\
\hline
\end{tabular}

Wenn man z. B. den Zeitpunkt, wo die Kontrolle 9 vollkommen gelöst ist, als maßgebend ansieht, so ist das Ochsenserum komplementbindend. Betrachtet man aber eine Frist von zwei Stunden als notwendig zur Erzielung eines definitiven Resultates, so ist in diesem Falle das Ergebnis ein negatives. Aus dem Vergleich mit dem luetischen Serum erkennt man. 
daß bei stark wirksamen Seris ein Aufenthalt von zwei Stunden bei $37^{\circ}$ keine Lösung herbeiführt. Diejenigen Röhrchen, welche nach zwei Stunden entweder vollkommen gelöst sind oder höchstens Spuren von ungelöstem Blut enthalten, sind als negativ zu bezeichnen.

\section{Versuche, bei denen im Laufe der Trypanosomeninfektion das Bordet-Gengousche Phänomen eintrat.}

1. Kaninchen 96a. Serum rom 21. Dezember 1907 0,2 - vollständige Hämolyse.

Am 21. Dezember mit Dourine infiziert. Trypanosomen am 28. Dezember nachgewiesen.

17. Januar 1908. Serum 0,2, starke Hemmung.

26. Januar. Ebenso.

28. Januar. Serum 0,05 gibt vollkommene Hemmung.

Das Tier ist Ende Februar eingegangen.

Kaninchen $96 \mathrm{~B}$. Serum, am 18. Dezember 1907 entnommen, gibt, allein und mit alkoholischem Leberextrakt, keine Hemmung. Infiziert am 21. Dezember 1907 mit Dourine. Mikroskopisch sind bei diesem Tier bei wiederholter Untersuchung keine Trypanoscmen zu finden, doch ergibt eine Kontrollimpfung auf Ratten ihr Vorhandensein.

Serum vom 17. und 25. Januar 1908 . Keine Hemmung.

Serum vom 28. Januar 1908. 0,2 gibt sehr kleine Kuppe, 0,1 ohne Antigen vollständige Lösung.

Serum vom 6. Februar 1908. 0,2 kleine Kuppe, 0,1 vollkommene Lösung.

Serum vom 11. Februar 1908. 0,1 mittlere Kuppe.

Serum vom 20. März 1908. 0,2 kleine Kuppe.

Kaninchen 119 C. Vor der Impfung (3. Februar 1908). Serum

0,3: sehr kleine Kuppe.

Serum vom 23. März. 0.2 vollständige Hemmung.

Kuh No. 139. Am 15. Februar 1908. Serum $0,3-$ vollkommene

Hämolyse.

Am 17. Februar. Nagana intraperitoneal.

Am 27. Februar. Trypanosomen vorhanden.

Serum 0,3 starke Kuppe.

Serum 0,2 mittlere Kuppe.

Serum 0,1 vollkommene Hämolyse.

106a und b. Zwei Ratten am 31. Januar $1908 \mathrm{mit} \mathrm{Mal} \mathrm{de} \mathrm{Ca-}$ deras infiziert, am 3. Februar getötet (im Blut Trypanosomen).

a) Serum 0,2 - kleine Kuppe.

b) Serum 0,1 - mittlere Kuppe.

Siehe hierzu die Ratten $106 \mathrm{c}-\mathrm{g}$ unter II.

\section{Sera, bei denen im Verlauf der Trypanosom€ninfektion keine Ambozeptoren auftraten bzw. vor der Infektion vorhandene verschwanden.}

Kaninchen No. 41. Serum vom 7. Januar 1908: 0,1, große Kuppe! am 7. Januar mit Nagana infiziert. Serum vom 28. Januar: 0,2, sehr kleine Kuppe. Serum vom 21. Februar 1908: 0,2 vollkommene Hämolyse. Serum vom 6. März 1908: 0,2, fast vollkommene Hämolyse. Serum vom 16. März 1908: 0,2, vollkommene Hämolyse.

Kaninchen No. 42. (Serum am 7. Januar 1908 wurde mit zu schwachem Hämolysin geprüft.) Am 7. Januar 1908 mit Nagana infiziert. 20. Januar: 0,1, mittlere Kuppe. Serum allein: 0,1, kleine Kuppe. 21. Februar 1908: Serum 0,2, vollkommene Lösung. 6. März 1908: Serum 0,1, vollkommene Lösung. 16. März 1908: Serum 0,2, vollkommene Lösung.

Ochse 140 (siehe Tabelle I). Serum vor der Infektion 0,2, vollkommene Lösung. Am 17. Februar 1908 mit Nagana infiziert. Serum am 30. April 1908: 0,2, vollkommene Lösung. (Zweiter Versuch am 4. Mai 1908: Serum 0,2 - minimale Kuppe.)

153 a. Meerschweinchen, am 3. Februar 1908 mit Dourine geimpft. Am 2. März 1908 Trypanosomen vorhanden, getötet. Serum: 0,2 , vollkommene Hämolyse.

b) Meerschweinchen, ebenso wie 153 a. Serum am 3. Februar 1908: 0,2, vollkommene Lösung.

Meerschweinchen 50. Am 9. Januar 1908 mit Nagana infiziert. 24. Jamuar 1908: Serum 0,3 + alkoholischen Extrakt, vollkommene Lösung.

Meerschweinchen 51 a. Am 9. Januar 1908 mit Dourine infiziert. 23. Januar: Serum $0,3+$ alkoholischen Extrakt, vollständige Hämolyse.

Meerschweinchen 51 b. Am 9. Januar 1908 mit Dourine infiziert. 10. Februar: 0,3, vollständige Hämolyse.

Meerschweinchen 74 a. Am 18. Januar 1908 mit Nagana geimpft, am 25. Januar Trypanosomen vorhanden, getötet. Serum 0,3, vollständige Hämolyse.

Meerschweinchen $74 \mathrm{~b}$. Am 18. Januar 1908 mit Nagana infi ziert. Serum vom 22. Februar: 0,3 - vollkommene Hämolyse.
Meerschweinchen $74 \mathrm{c}$ wie $74 \mathrm{~b}$. Serum vom 22. Februar 1908: 0,3 - vollkommene Hämolyse.

Meerschweinchen 90a. Am 25. Januar mit Nagana infiziert. Serum vom 7. März (Trypanosomen ziemlich zahlreich): 0,2 - vollkommene Hämolyse.

Verschiedene alkoholische Extrakte, die gegenüber diesem und Luesserum geprüft wurden, ergeben für das Meerschweinchenserum negative, für das luetische Serum positive Resultate.

Meerschweinchen $90 \mathrm{~b}$ geimpft wie 90 a. Getötet 19. März 1908: 0,2 - vollkommene Lösung.

Meerschweinchen 101 a. Im Dezember 1907 mit Dourine infiziert. Serum vom 29. Januar 1908: 0,3 - vollkommene Hämolyse.

Meerschweinchen $101 \mathrm{~b}$ ebenso infiziert und entblutet wie $101 \mathrm{a}$ : 0,2 - vollkommene Hämolyse.

Meerschweinchen 120. Am 3. Februar mit Dourine infiziert. Serum vom 22. Februar: 0,3 - vollkommene Lösung.

$106 \mathrm{c}$ und d. Zwei Ratten, am 31. Januar 1908 mit Caderas in. fiziert; am 3. Februar im Blut Trypanosomen. Am 4. Februar getötet. Serum c und d: 0,3 - rollkommene Hämolyse.

$106 \mathrm{e}$ und f. Zwei Ratten, wie $106 \mathrm{c}$ und $\mathrm{d}$ infiziert. Am 5. Februar getötet. Serum e und f: 0,2 - vollkommene Hämolyse.

$106 \mathrm{~g}$ wie $106 \mathrm{c}$ und $\mathrm{d}$ infiziert. Am 3. und 4. Februar mit je 0,01 Atoxyl subkutan injiziert; die Trypanosomen sind aus dem peripherischen Blute verschwunden. Am 10. Februar getötet. Serum: 0,3 - vollkommene Hämolyse.

174 a. Bunte Ratte, am 3. März 1908 mit Dourine geimpft; am 6. März sehr viele Trypanosomen; Tier moribund. Serum: 0,2 vollkommene Hämolyse.

b) Ratte, am 3. März mit Dourine geimpft. Am 7. März 1908 moribund. Serum: 0,2 - kleine Kuppe. Serum 0,1 - vollkommene Hämolyse.

\section{Normale Kauinchensera.}

Kaninchen 129 a Serum 0,2 + alkohol. Extrakt: kleine Kuppe $0,1+\quad, \quad$ : vollk. Lösung 0,2 allein vollkommene Lösung.

Kaninchen 129b Serum 0,2 + alkohol. Extrakt: kleine Kuppe $0,1+\cdots \quad$ : vollk. Lösung 0,2 allein vollkommene Lösung.

Versuch 32 a. Kaninchenserum 0,1 + alkohol. Extrakt: vollstándige Hemmung

Serum allein 0,1 hemmt stark.

Versuch 33. Kaninchenserum $0,1+$ alkohol. Extrakt: vollständige Hemmung.

Serum 0,1 allein hemmt stark.

Versuch 32 b Kaninchenserum $0,1+$ alkohol. Extrakt: vollständige Hemmung.

Serum allein 0,1 hemmt stark.

Kaninchenserum 118a b und $\mathrm{c}$ normal 0,1 + alkohol. Extrakt: vollständige Hemmung.

Serum 0,1 allein: kleine Kuppe.

Kaninchenserum 119 a normal 0,1 + alkohol. Extrakt: vollständige Hemmung.

Serum 0,1 allein: mittlere Kuppe.

Kaninchenserum 119 b 0,2 + alkohol. Extrakt: Mittlere Kuppe $0,1+\quad$ : sehrkleineKuppe

0,1 allein vollkommene Lösung.

Kaninchenserum 119 c 0,3 + alkohol. Extrakt: sehr kl. Kuppe. 0,1 allein - vollständige Lösung.

Kaninchenserum 129 b u. c vom 10. Februar 0,2: kleine Kuppe 0,1 vollkommene Hämolyse.

Aus diesen Versuchen ergibt sich folgende Tabelle:

I. Positiv: Kaninchen 96a 0,1 vollkommene Hemmung 38 Tage nach der Infektion.

Kaninchen 96 b 0,1 mittlere Kuppe (11. Februar 1908) 52 Tage nach der Intektion.

Kaninclien 109c 0,2 vollständige Hemmung (23. März 1908) (49 Tage nach der Infektion.)

Kaninchen 139 0,2 mittlere Kuppe (27. Februar), 10 Tage nach der Infektion.

Ratte 106 a 3 Tage nach der Infektion 0,2 kleine Kuppe.

Ratte 106 b 3 Tage nach der Infektion 0,1 mittlere Kuppe.

II. Negativ: Kaninchen 41. 42 .

Meerschweinchen $153 \mathrm{a}, 153 \mathrm{~b} ; 50 ; 51 \mathrm{a}, 51 \mathrm{~b} ; 74 \mathrm{a}, 74 \mathrm{~b}, 74 \mathrm{c}$; $90 \mathrm{a}, 90 \mathrm{~b} ; 101 \mathrm{a}, 101 \mathrm{~b} ; 120$.

Ratten $106 \mathrm{c}, 106 \mathrm{~d}, 106 \mathrm{e}, 106 \mathrm{f},(106 \mathrm{~g}) ; 174 \mathrm{a}$ u. $174 \mathrm{~b}$.

Ochse 140.

Normale Kaninchensera.

$$
\begin{aligned}
& 129 \mathrm{a}-0,2 \text { kleine Kuppe } \\
& 129 \mathrm{~b}-0,2
\end{aligned}
$$


$32 \mathrm{a}-0,2$ vollständige Hemmung

$$
\begin{aligned}
& 32 \mathrm{~b}-0,1 \\
& 33-0,1 \\
& 118 \mathrm{a}-0,1 \quad " \\
& 118 \mathrm{~b}-0,1 \quad " \\
& 118 \mathrm{c}-0,1 \quad " \\
& 119 \mathrm{a}-0,1 \\
& 119 \mathrm{~b}-0,2 \text { mittlere Kuppe." } \\
& 119 \mathrm{c}-0,3 \text { sehr kleine Kuppe. } \\
& 129 \mathrm{~b}-0,2 \text { kleine Kuppe. } \\
& 129 \mathrm{c}-0,2 \quad "
\end{aligned}
$$

Den drei Kaninchen, bei welchen die das Komplement bindenden Ambozeptoren im Laufe der Infektion auftraten, stehen sieben Kaninchen, bei denen schon normalerweise vollkommene Hemmung der Hämolyse auftrat, gegenüber. Diese Ambozeptoren, deren Natur noch so wenig aufgeklärt ist, unterliegen auch bei normalen Kaninchen bedeutenden Schwankungen, vielleicht infolge ungleichmäßiger Ernährung. Der Versuch mit Kaninchen 41 spricht dafür, daß positive und negative Reaktion bei dem gleichen Tiere vorkommen. Jedenfalls ist der Schluß gerechtfertigt, daß Kaninchen zu solchen Versuchen nicht geeignet sind.

Bei zwei Rindern ist einmal eine positive (139), einmal eine negative Reaktion (140) erzielt worden.

Bei $z$ wei Ratten, welche $3 \times 24$ Stunden nach der Infektion getötet worden waren, fand sich eine schwache bzw. mittelstarke Reaktion. Im Gegensatz dazu fiel bei 6 weiteren Ratten, die 4 bzw. 5 Tage nach der Infektion getötet worden waren, die Reaktion negativ aus. Ebenso bei Ratten, in deren Blut die Trypanosomen durch A toxyl aufgelöst worden waren. 13 Meerschweinchen, deren Serum 1 bis 6 Wochen nach der Trypanosomeninfektion geprüft wurde, ergaben niemals einen positiven Ausschlag, obwohl die Sera mit wirksamen Extrakten verschiedenster Provenienz, auch mit solchen Trypanosomen-infizierter Tiere geprüft worden waren. Da das normale Meerschweinchenserum niemals für sich allein Hemmung der Hämolyse hervorruft, so wären Meerschweinchen, bei denen die Trypanosomeninfektion exquisit chronisch verläuft, ganz besonders geeignet, um eventuell vorhandene Ambozeptoren nachzuweisen.

Der negative Ausfall der Versuche mit Meerschweinchen beweist, daß für die Praxis die Bordet-Gengousche Methode, so wie wir sie in unseren Versuchen zur Anwendung brachten, ohne Bedeutung ist. Erwähnt soll noch werden, daß auch bei normalen Tieren, speziell Kaninchen, eine Präzipitation durch Lecithin (nach Porges und Meier) manchmal stattfindet, sodaß auch diese Methode als nicht zuverlässig angesehen werden kann.

Dazu kommt noch, daß bei der Trypanosomiasis des Menschen ein positiver Ausfall der Reaktion bei Verwendung der üblichen Antigene (wäßrige und alkoholische Extrakte aus luetischen oder normalen Lebern) auch als Reaktion auf Syphilis gedeutet werden kann. Die Syphilis ist unter den Negern Aequatorialafrikas so stark verbreitet, daß sie bei keinem Individuum mit voller Sicherheit ausgeschlossen werden kann. Damit würde die praktische Verwertbarkeit der Reaktion noch weiter reduziert.

Doch soll hiermit nicht gesagt sein, daß diese Methode ein für allemal wertlos sei. Es ist nämlich sehr wohl möglich, daß bisher bei allen derartigen Versuchen nicht das richtige Antigen zur Verwendung kam. Versuche nach dieser Richtung sind bereits im Gange.

Literatur. Levi della Vida, La deviazione del complemento etc. Ann. d'Igiene speriment. Bd. $17, \mathrm{~S} .689$. - Levadit $\mathrm{i}$ und $\mathrm{Y}$ a $\mathrm{m}$ a n o u $\mathrm{ch} \mathrm{i}$, La reaction de la déviation du complement dans la maladie du sommeil. Bulletin de la société de pathologie exotique Bd. I, S. 26. - L evadit $i$ und $Y$ a m a n o u c h $i$, La rection de pathologie exotique Bd. I, S. 26. - L e vadit $i$ und $Y$ a $m$ a $n$ o $u c h i$, La réaction
des llpoides etc. Bulletin de la societe de pathologie exotique Bd. I, S. 140. - L a nd. s te in er, M ì ll er und P $\delta$ t $z$ l, Wieller klinische Wochenschrift 1907, S. 1421 u. 1565. - Wassermann und $M$ eier, Zur klinischen Verwertung der Serumdiagnose bei Lues. Deutsche medizinische Wochenschrift 1907, No. 32. - Porges und $M$ e i e r, Ueber die Rolle der Lipoide etc. Berliner klinische Wochenschrift 1908, No. 15. Fleis chma n n, Zur Theorie und Praxis der Serumdiagnose der Syphilis. Berliner klinische Wochenschrift 1908, No. 490. - B i u me n thal, Diskussionsbemerkung in Berliner klinische Wochenschrift 1908, S. 618 . 